\title{
How to Improve the Likelihood of CDM Approval? Institutional shortcomings and the Case of West Africa
}

\author{
Urs Steiner Brandt \\ Department of Environmental and Business Economics \\ University of Southern Denmark, Denmark \\ E-mail: usb@sam.sdu.dk
}

Gert Tinggaard Svendsen

Department of Political Science and Government, Aarhus University, Denmark

E-mail: gts@ps.au.dk

Received: November 1, $2013 \quad$ Accepted: November 11, 2013

doi:10.5296/emsd.v3i1.4492ＵRL: http://dx.doi.org/10.5296/emsd.v3i1.4492

\begin{abstract}
How can the likelihood of Clean Development Mechanism (CDM) approval be improved in the face of institutional shortcomings? To answer this question, we focus on the three institutional shortcomings of income sharing, risk sharing and corruption prevention concerning afforestation/reforestation (A/R). Furthermore, three main stakeholders are identified, namely investors, governments and agents in a principal-agent model regarding monitoring and enforcement capacity. Developing countries such as West Africa have, despite huge potentials, not been integrated in A/R CDM projects yet. Remote sensing, however, appears to be an effective tool to overcome the three institutional shortcomings. Thus, a pilot project should be considered in near future to develop a best practice system.
\end{abstract}

Keywords: Clean Development Mechanism, institutions, remote sensing, corruption, income sharing, risk sharing, afforestation, reforestation, West Africa, principal-agent, pilot project.

\section{Introduction}

The global forests are declining. The Global Remote Sensing Survey shows that the world's total forest area in 2005 was 3.69 billion hectares, or $30 \%$ of the global land area. The average rate of world deforestation between 1990 and 2005 is estimated at 14.5 million hectares per year, which translates into a current forest loss of approximately $0.4 \%$ per year. Deforestation largely occurs in the tropics as tropical forests are converted to agricultural 
land (FAO, 2012).

A non-sustainable managed forest area implies loss of ecosystem services such as food, water for drinking and irrigation, stocks of genetic resources, aesthetics, habitats for humans and wildlife, soil creation and life support functions. Moreover, and most relevant in this context, deforestation increases the $\mathrm{CO}_{2}$ stock in the atmosphere, and the international community is considering mechanisms to reverse this process (Perman et al. 2011).

The UNFCCC has established two mechanisms to reduce the net-release of $\mathrm{CO}_{2}$ from forests: First REDD+ (reduced emission from deforestation and reduced degradation) and second $\mathrm{CDM}$ (the Clean Development Mechanism). REDD+ aims to slow down $\mathrm{CO}_{2}$ release, and $\mathrm{CDM}$ addresses afforestation and reforestation (A/R) projects to increase the storage (sequestration) of carbon by increasing forest biomass, see e.g., Palmer (2011) and Lederer (2011) for an overview of REDD+ and CDM. Both are part of the broader idea of LULUCF: land use, land use change and forestry. Including it into viable mechanisms for addressing climate change and sustainable development is an ongoing political issue, see e.g., Höhne et al. (2007). The potential of REDD for climate policy and distribution of wealth is analyzed in Anger et al (2012). A REDD+ methodology is, however, not fully developed yet, and so far only few pilot projects have been initiated (Lederer, 2011). We will therefore focus on CDM rather than REDD+, as several small and large-scale reforestation projects have already been launched (Thomas et al. 2010; Paulsson 2009).

Our research question is: How can the likelihood of CDM approval be increased in the face of institutional shortcomings? We will answer this question by focusing on three institutional shortcomings, namely income sharing, risk sharing and corruption prevention. Thomas et al. (2010) find that a feature of "successful" A/R CDM projects is to share income and direct most revenue from CERs back to the local community. As far as risk sharing, Gong (2010) point to large uncertainties that often discourage small-scale and poor land users in developing countries from making long-term and often expensive investments in forestry. Finally, UNEP (2013) recognized that corruption is an impediment to effective environmental stewardship.

The CDM project allows non-industrialized countries to take part in climate mitigation through the formation of carbon projects which can be registered and produce Certified Emissions Reduction (CERs) credits. It is then possible for industrialized countries to acquire these carbon credits by financing emission reduction projects in developing countries (Walker et al. 2008). In other words, industrialized countries with a greenhouse gas reduction commitment, may invest in these projects, such as replanting forests that reduce emissions in developing countries. The CDM is thus overall an economic instrument that serves to reduce global greenhouse gas emissions at a lower cost.

The CDM has a large potential, and 7912 CDM projects are now included in the pipeline. The number of available CERs in 2008-2012 is estimated at 232 million compared to 865 million for 2013-2020 (start 2012). Of these, only $0.8 \%$ are reforestation projects and only $0.2 \%$ of total expected reduction units (ERU) (Risoe, 2012). To our knowledge, the literature has not yet addressed this huge CDM potential. For example, the current climatic changes in 
Africa are predicted to increase in severity over the next decades, posing a severe threat to the economies and the livelihoods of millions of people who live in rural districts. Lykke et al. (2009) point out that arid, semi-arid and dry sub-humid areas, which cover $43 \%$ of Africa and maintain $40 \%$ of the population, are particularly vulnerable to climate change. Many people here live by subsistence farming in a barely cultivatable environment, and the national governments have limited economic means to assure food security. Thus, as argued by Chhatre and Agrawal (2009), forests provide not only the global public good of carbon sequestration but are also associated to livelihood benefits to more than half a billion poor people.

According to Cormier and Bellassen (2013), the approval rate (fraction of produced CERs to the emissions reductions specified in the original product design documents) is only about $30 \%$, and even smaller for afforestation/reforestation (A/R) projects. UNFCCC has largely abandoned CDM projects in Africa, such as reforestation, as means to create carbon credits, because of problems with information (observation of growth in biomass), with baseline calculations, with verification of changes in biomass and incentive problems (Torres et al., 2010; Buchner 2008; Cormier and Bellassen, 2013).

In the following, we answer the research question by modelling the incentive scheme in a CDM project, such as investment in reforestation. Kanowski et al. (2011) emphasize the necessity of developing principles of good forest governance based on earlier failures so that these new adequate mechanisms can implement the necessary institutional reforms needed if projects are to succeed. Remote sensing is one first major step in this direction. Given the availability of remote sensing, we design an incentive system that contains risk and profit sharing between investor and local workers, requires minimum institutional infrastructure and therefore is less vulnerable to inefficiency and corruption. We argue that projects of this type should have a much higher approval rate than the current A/R CDM projects in Africa. The issue of remote sensing is also addressed by Brandt and Svendsen (2013a), who argue that new and advanced satellite measurement techniques may help overcome practical monitoring problems of measuring the size of biomass and avoid institutional problems, for example in African countries. However, the current analysis focuses on the CDM's multilayer problem and institutional shortcomings, while Brandt and Svendsen (2013a) focus on the potential of differentiated payment structures to generate higher benefits and more sustainable projects.

Since CDM arrangements are based on voluntary contracting, and in several ways resample a principal-agent model, we apply this methodology to analyze the effect of remote sensing on the prospect of increasing the approval rate of A/R CDM. We can interpret the investor as the principal who benefits from the output, while the local farmers are the agents who receive a payment from the principal to produce the output, i.e. $\mathrm{CO}_{2}$ - uptake. There are, however, additional elements to consider compared to the traditional principal-agent setting. Without remote sensing, there are very limited possibilities to contingent payment to the agent on output. Therefore, direct surveillance of the agents' effort is needed. We assume that the local governmental supervision institutions will be in charge of undertaking this surveillance. Since both the agent and government have incentive the overstate agent effort, room for corruption exist. Moreover, without being able to measure output, both risk and income sharing is 
limited. However, when remote sensing is added, we show how an incentive contract can be designed to provide income, risk sharing and prevention of corruption.

Section 2 presents the economic gains from the CDM under full information in a principal-agent model. Section 3 develops a model which focuses on the three institutional shortcomings of income sharing, risk sharing and corruption prevention. Furthermore, the case of West Africa is considered as a potential pilot project. Section 4 gives a conclusion.

\section{Potential Economic Gains from the CDM under Full Information}

Since a CDM arrangement is a voluntary arrangement, we start by explaining why both seller and buyer should, in theory, gain from this type of carbon trading. We only consider so-called unilateral projects, i.e., projects developed only by the host investor, who may be a national or international firm or a public institution.

A necessary condition for the profitability of a CDM project is that a project exists in the host country that contains cheaper reduction potentials than a project in the investor country. For example, it is often cheaper to reduce carbon emissions in Burkina Faso than in Europe. There are reasons to expect that the EU faces significantly higher marginal reduction costs because of its more expensive technology options. For example, EU does not have the option of launching low-cost, large-scale agricultural projects: EU has already picked all low-hanging fruits and is forced to turn to relatively expensive technological alternatives such as improved energy efficiency, fuel switching, and wind and solar energy. Moreover, it is obligated to reduce its $\mathrm{CO}_{2}$ emissions by specific target levels under the Kyoto Protocol. In contrast, Burkina Faso has the option of launching low-cost agricultural projects such as reforestation and thereby sequestrates carbon, and the country is not committed under the Kyoto Protocol.

Consider that the investing group in a country is subject to the EU Emission Trading System (ETS). In a well-functioning ETS market, the marginal costs of all sources are equalized and equal to the permit price in the market. Therefore, if we assume that the number of allowances earned in the project is so small compared to the total volume in the market that the market price is unaffected, the value of the allowances received from the project is equal to the permit price in the permit market.

Besides the benefits in terms of generated CERs, a number of costs must be included: operation, surveillance and maintenance costs, including labour, investments, perhaps payment for consultancy services for the complicated development of project documentation, and finally, the opportunity cost of the land. The opportunity cost of the land is particularly important in connection with forestation, since the land could have been used for other purposes. Potential benefits and costs from a CDM project can be summarized as follows:

Benefits

- The value of the permits (price in the permit market times volume of the project in terms of CER)

- The value of harvesting 


\section{Macrothink}

- Costs

- Investment costs

- Operations and maintenance costs, including labour costs

- $\quad$ Surveillance costs

- Opportunity costs

- Opportunity cost of the land

We focus exclusively on a situation where the size of the project is fixed. We then consider how to maximize the number of CERs of the project by managing the biomass growth and, hence, the implied $\mathrm{CO}_{2}$ uptake. We therefore also treat investment costs (but not surveillance costs) and opportunity costs as fixed costs.

We assign the CDM project a principal-agent structure. The main parties in the arrangement are the investor, the local government, and the local workers responsible for the growth (maintenance) of the forest. The investor initiates the project and charges the agents, i.e., the local community workers, with maintaining the forest in a way that maximizes the outcome of the investment. This results in a principal-agent structure.

Let local farmer, denoted agent, put effort, $e_{a}$, into the project (planting, maintaining the forest, preventing illegal logging, etc.). Effort is assumed to be a one-dimensional variable measured in hours. More effort implies higher biomass, to be specified below. Moreover, $w_{a}$ denotes the wage per hour paid to the agent for working on the CDM project.

We will use the following relationships to describe the essential links in our model. Total biomass produced in the contracting period, denoted $B M^{p}$, consists of two parts, one independent of agent effort and one increasing in agent effort. (For simplicity, assume the two parts are independent). $B M(0)$ is the benchmark (baseline) biomass, that is, the size of the biomass without the project. For simplicity, and without any loss of generality, we normalize $B M(0)=0$.

$$
B M^{p}=B M\left(e_{a}\right)
$$

Effort increases biomass, but at a decreasing rate: $B M_{e_{a}}^{\prime}>0, B M_{e_{a}}^{\prime \prime}<0$.

The second link in our model is a biological relationship between biomass and $\mathrm{CO}_{2}$ storage, denoted $\mathrm{CO}_{2} \mathrm{~S}$. We simply assume a linear relationship, where $\alpha_{S}>0$ is a constant:

$$
\mathrm{CO}_{2} \mathrm{~S}=\alpha_{S} \cdot \mathrm{BM}\left(e_{a}\right)
$$

The third link is between the produced CERs and $\mathrm{CO}_{2}$ storage. Again, we assume a linear relationship, where $\alpha_{C}>0$ is another constant: 


$$
C E R=\alpha_{C} \cdot \mathrm{CO}_{2} \mathrm{~S}
$$

Combining (2) and (3) yields the relationship between agent effort and CERs, where $\alpha=\alpha_{S} \cdot \alpha_{C}$ :

$$
\operatorname{CER}\left(e_{a}\right)=\alpha \cdot B M\left(e_{a}\right)
$$

From (1) and the linearity of (2) and (3), it immediate follows that ${ }^{C E R_{e_{a}}^{\prime}}>0$ and $C E R_{e_{a}}^{\prime \prime}<0$.

This means that a greater effort increases the number of CERs but at a decreasing pace. According to Paarsch and Shearer (1996), the reason that increased effort (time) increases the quality of the forest is that the beneficiaries of tree-planting are mainly concerned with two aspects of output from agents: quantity and quality. While quantity is important for obvious reasons, the quality of planted seedlings determines the survival rate of those seedlings. The survival of seedlings depends on several aspects of the planting process: an acceptable planting spot; adequate spacing between newly planted trees, between newly planted trees and existing trees; the actual planting spot must be prepared correctly, i.e., the planting hole must be deep enough and wide enough to ensure that the root system will not be damaged during planting. Finally, the seedling must be placed vertically into the planting hole so that the roots are not folded over, and the hole must be filled in and firmly tamped down. For obvious reasons, increases in effort (at least after some point) reduce the speed with which the biomass grows.

The net benefit of a size $A$ project, and fixed parameter in the relationships (1)-(3) is now dependent on effort of agents, written as $B\left(e_{a}\right)$. This is equal to the amount of $\mathrm{CO}_{2}$ allowances earned, given effort $\left(e_{a}\right)$ put into the project by the agents, $\operatorname{CER}\left(e_{a}\right)$, times the allowance price, $p^{E T S}$, plus the value of harvesting, $h(A)$, which we here let depend only on the size of the project.

$$
B\left(e_{a}\right)=p^{E T S} \cdot \operatorname{CER}\left(e_{a}\right)+h(A)
$$

The direct costs, $D C\left(e_{a}\right)$, from the project are the wage $\left(w_{a}\right)$ paid to workers/agent, and fixed costs including investment costs and opportunity costs and what is sometimes called quasi fixed costs, like materials, resources, maintenance, etc., all summarized in $F C(A)$. We assume therefore that none of these costs are dependent on the effort exerted by the agent,

$$
D C\left(e_{a}\right)=w_{a} \cdot e_{a}+F C(A)
$$

The direct net benefit, $\operatorname{DNB}\left(e_{a}\right)$, from the project is found by subtracting (6) from (5):

$$
\operatorname{DNB}\left(e_{a}\right)=p^{E T S} \cdot \operatorname{CER}\left(e_{a}\right)+h(A)-w_{a} \cdot e_{a}-F C(A)
$$




\section{Macrothink}

Environmental Management and Sustainable Development

ISSN 2164-7682

2014, Vol. 3, No. 1

The term "direct net benefit" is used here because it denotes a situation where the effort is directly observable for the investor and therefore it is possible to base any incentive contract with the agent directly on this observed agent effort.

In this section we assume that effort is fully observable. We will alter this assumption in the next section, since this is our main research agenda. Consider first that $w_{a}$ is exogenous for the investor. Optimal effort is derived by maximizing (7) with respect to agent effort yields: $\frac{d D N B}{d e_{a}}=p^{E T S} \cdot C E R_{e_{a}}^{\prime}-w_{a}$. From this we can derive the first order condition for optimal effort:

$$
e_{a}^{*}: C E R_{e_{a}}^{\prime}=\frac{w_{a}}{p^{E T S}}
$$

The project will be undertaken if $\operatorname{DNB}\left(e_{a}^{*}\right)>0$.

Now consider that the investor can determine the wage for the agent. The local farmers(or the local community)should, at least, be compensated for their work by the opportunity costs of their labour. Consider that agents have an outside opportunity that pays $r_{a}$ and that they can work maximum $L$ hours per period (days, weeks, months). We assume that the agents always work $L$ hours per period at the job that pays the highest wage. The agents are being paid by the project (investor) according to the effort they put into the project. Finally, if harvesting from the "carbon-capture forest" is feasible, the value of this should be subtracted. Letting both paid $r_{a}$ and $w_{a}$ be fixed, and letting harvesting income be measured in $€ /$ period, the individual rationality constraint for the agents reads:

$$
w_{a} \geq r_{a}-h(A)
$$

The investor will solve the following maximization program:

$$
\max _{e_{a}} \operatorname{DNB}\left(e_{a}\right)=p^{E T S} \cdot \operatorname{CER}\left(e_{a}\right)+h(A)-w_{a} \cdot e_{a}-F C(A)
$$

Subject to

$$
w_{a} \geq r_{a}-h(A)
$$

If the investor has full bargaining power in the negotiation over how to split the net benefit from the relationship, an economically rational investor setsw $w_{a}=r_{a}-h(A)$, and thereby fully extracts all surplus from the arrangement. We can directly use (8) to find the optimal $e_{a}$ :

$$
e_{a}^{*}: C_{E} R_{e_{a}}^{\prime}=\frac{r_{a}-h(A),}{p^{E T S}}
$$

The problem now consists of two distinct issues: We need to determine the payment such that all three players are willing to participate, and we need to find an incentive (motivation) structure to ensure that the efficient level of allowances is produced.

Figure 1 shows the solution graphically. Given that the marginal benefit is decreasing while the marginal costs are constant, there will be a solution given that $\operatorname{DNB}\left(e_{a}^{*}\right)>0$. 


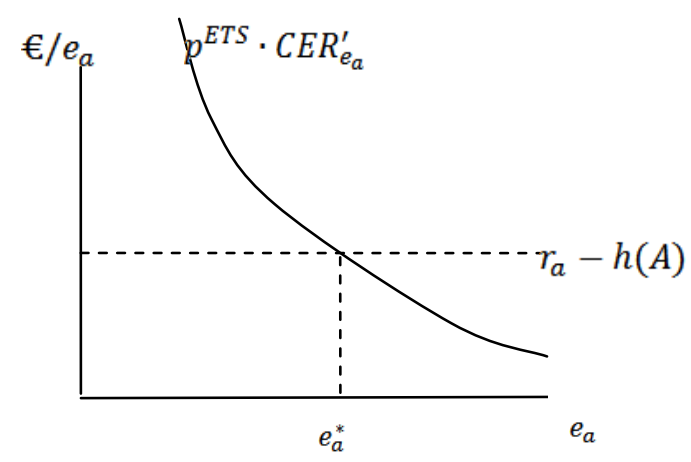

Figure 1. Optimal effort in the base case

What remains is the issue of how to design an incentive structure such that $e_{a}^{*}$ will be the true effort level in case of private information or when it is impossible to directly control the efforts.

\section{Incentive Schemes}

\subsection{The Principal-agent Problem}

The problem of motivating a party to act on behalf of another is known as "the principal-agent problem". It arises when a principal compensates an agent for performing certain acts that are useful to the principal and costly to the agent and when it is costly to observe elements of the performance.

Consider now the situation where it is not possible to observe the growth in the biomass directly, or the effort of the agent, but the local government provides a monitoring capacity and enforcement mechanism. We propose that the project will only succeed if the government is involved. The government can send inspectors to measure the effort and, based on this, deduce the output. In case the desired effort is not observed, credible sanctions could be imposed to realize the optimal output.

The arrangement still resembles a principal-agent model, but with an additional layer of hierarchy, denoted a principal-supervisor-agent problem, as shown in Figure 2. In our CDM model, the principal is a group of investors in the EU, the supervisor is the host country, which also has the power to enforce agent behaviour, and the agent is the persons in charge of planting and maintaining the agricultural project. The additional layer will, however, only be relevant in cases in which it is not possible to observe the growth of the biomass.

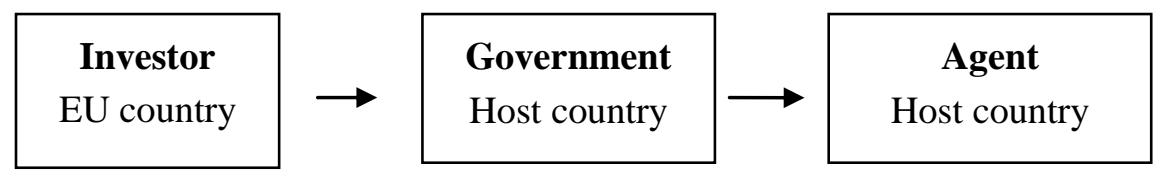

Figure 2. The relationship is a (three layer) principal-agent relationship 


\section{Macrothink}

At the very heart of a principal-agent relationship are the diverging objectives of the principal and the supervisor. Therefore, the principal needs to motivate the self-interested supervisor to act in the principal's interests. The solution for the principal is to "change the rules of the game" to strengthen the alignment of interests between principal and agent. The main information problem in a CDM arrangement is that it is not possible to observe the growth in biomass and the effort put into forestry.

We consider two types of incentive contracts to overcome these difficulties. In the first type, it is not possible to observe growth in biomass and the agents' effort, so the government has to provide the necessary monitoring and enforcement capacity. In the second type, it is possible to monitor output directly via remote sensing, enabling the investor to circumvent the government supervision process.

\subsection{Modelling a CDM arrangement when government surveillance is needed}

We assume here that the government is responsible for surveillance and enforcement of the contract, if necessary. Government effort to monitor and enforce agent behaviour is denoted $e_{g}$. An opportunity cost on government is given by $w_{g} \cdot{ }^{1}$ The fundamental relationship between government and agent effort is captured by the following relationship:

$$
e_{a}=e_{a}\left(e_{g}\right)
$$

Importantly, when the government's effort is increased (better monitoring, more enforcement, etc.), the agents' effort is also increased, but at a decreasing pace. That is, assume that $\left(e_{a}\right)_{e_{g}}^{\prime}>0$ and $\left(e_{a}\right)_{e_{g}}^{\prime \prime}<0$.

To compare with the situation where government agents are not needed, we still want to express the net benefit as a function of agent effort. To do this, we need to find the inverse of $e_{a}=e_{a}\left(e_{g}\right)$, denoted by $e_{g}{ }^{-1}\left(e_{a}\right) .^{2}$

To finish this part, we consider that without any surveillance, $e_{a}=0$. We can now formulate the net benefit function in this case, consisting of the direct net benefit and payment to the government:

$$
N B\left(e_{a}\right)=p^{E T S} \cdot \operatorname{CER}\left(e_{a}\right)+h(A)-w_{a} \cdot e_{a}-w_{g} \cdot e_{g}{ }^{-1}\left(e_{a}\right)-F(A)
$$

Letting the investor maximize $N B\left(e_{a}\right)$, again setting $w_{a}=r_{a}-h(A)$ yields the new first order condition:

\footnotetext{
${ }^{1}$ We assume throughout that the government uses its effort optimally, i.e., the tasks of monitoring and enforcing are chosen in a cost-effective manner.

${ }^{2}$ I.e., let $e_{a}=e_{a}\left(e_{g}\right)=k \cdot \sqrt{e_{g}} \cdot e_{g}=e_{g}{ }^{-1}\left(e_{a}\right)=\frac{e_{a}^{2}}{k^{2}}$
} 


$$
e_{a}^{+}: P^{E T S} \cdot C E R_{e_{a}}^{\prime}=w_{a}+w_{g} \cdot \frac{\partial e_{g}^{-1}\left(e_{a}\right)}{\partial e_{a}}
$$

The project will be profitable if $N B\left(e_{a}^{+}\right)>0$.

Since $\left(e_{a}\right)_{e_{g}}^{\prime}>0, \frac{\partial e_{g}^{-1}\left(e_{a}\right)}{\partial e_{a}}>0$, it follows that $e_{g}^{*}>e_{g}^{+}$. Moreover, and $\left(e_{a}\right)_{e_{g}}^{\prime \prime}<0$ implying that $\frac{\partial^{2} e_{g}-1\left(e_{a}\right)}{\partial\left(e_{a}\right)^{2}}>0$, the result is that more and more government effort is needed to increase agent effort additionally.

As a consequence, it becomes increasingly costly to obtain a greater effort from the agents, and less agent effort compared to the case where agent effort is directly observable, because the additional convex cost component reduces the optimal effort (see figure 3). So if the investor has to compensate the government for its surveillance costs, the provision of additional (agent) effort is more costly to the investor. The implication is less growth in the biomass and fewer CERs from the project since the investor will settle for a situation where less additional biomass is produced. In Figure 3, the extra costs are indicated as the shared area $\mathrm{A}$, while the total benefit is area $\mathrm{C}$. If agent effort is observable, then the net benefit from the arrangement is given by the areas $\mathrm{A}+\mathrm{B}+\mathrm{C}$ minus the fixed costs $F(A)$, while in the government surveillance case the net benefit is area $\mathrm{C}$ minus fixed costs. The implication is that for all projects where $F(A) \in(C, A+B+C)$ projects will only be realized when agent effort is observable.

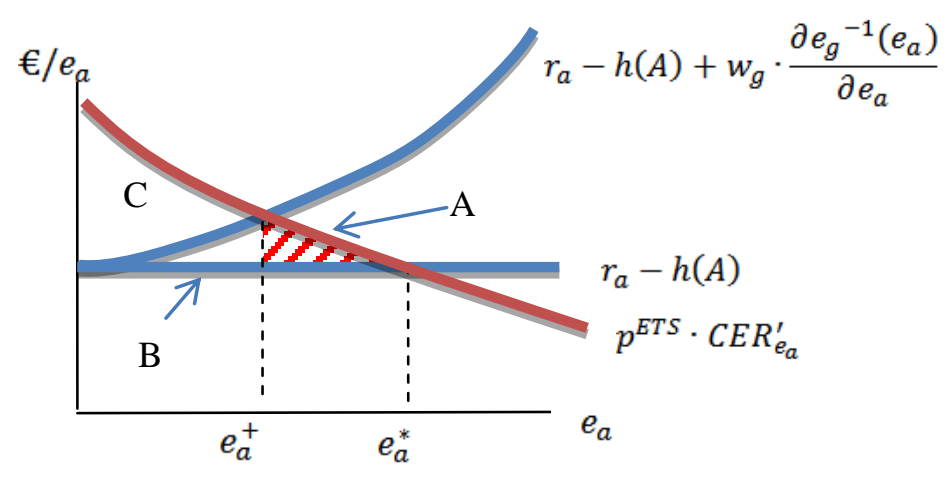

Figure 3. Optimal effort in the directly observable and non-observable effort cases

In this approach, it is implicitly assumed that no incentive scheme is needed to guarantee that the government agents (supervisors) will make the required effort to secure that the worker agent indeed makes $e_{a}^{+}$amount of effort. Can we claim that the relationship $e_{a}=e_{a}\left(e_{g}\right)$ ? A typical problem here is corruption. The supervisor and the agent have alignment of incentives to claim that agent effort is higher than real effort. The agents then receive a surplus (higher payment than implied by their effort) which can be divided with the supervisor. Due to these 


\section{Al Macrothink}

Environmental Management and Sustainable Development

ISSN 2164-7682 2014, Vol. 3, No. 1

types of incentive problems, the international community finds such arrangements unacceptable for use under the Kyoto Protocol. Consequently, other mechanism schemes need to be employed to generate "acceptable" CERs. This is the issue of the next section.

\subsection{Observable Growth in Biomass via Remote Sensing}

Now, consider the second situation where the investor cannot observe the agent directly but can observe the growth in biomass and hence the net uptake of $\mathrm{CO}_{2}$ of the forest.

Given the fundamental relationship, $B M=B M\left(e_{a}\right)$, and as we assumed that $B M$ is monotonically increasing in $e_{a}$, it is possible to deduce the agents' effort based on observation of growth in the biomass. Since $B M=B M\left(e_{a}\right)$ and therefore $e_{a}=B M^{-1}\left(e_{a}\right)$, we can derive the agents' effort from observing the growth in biomass and construct an incentive contract contingent on observed biomass.

As shown in section 2, the optimal effort is $e_{a}^{*}$ with resulting biomass from effort given by $B M\left(e_{a}\right)=B M\left(e_{a}^{*}\right)$. How do we construct an incentive scheme that has a high likelihood of achieving $B M\left(e_{a}^{*}\right)$ and is attractive to the agents?

Our simple solution is to make an arrangement where agents and investor share the net benefit.

First, a look at investor profit: $\Pi^{I}\left(e_{a}\right)=p^{E T S} \cdot \operatorname{CER}\left(e_{a}\right)-w_{a} \cdot e_{a}-F(A)$. Consider now that a fraction $\beta \in(0,1]$ of $\Pi^{I}\left(e_{a}\right)$ is given to the agents. It is easy to derive that it is still optimal for the investor to choose $e_{a}^{*}$. That follows because:

$$
\begin{gathered}
(1-\beta) \cdot \Pi^{I}\left(e_{a}\right)=(1-\beta) \cdot\left[p^{E T S} \cdot \operatorname{CER}\left(e_{a}\right)-w_{a} \cdot e_{a}-F(A)\right] \\
\frac{d \Pi^{I}\left(e_{a}\right)}{d e_{a}}=(1-\beta) \cdot\left[p^{E T S} \cdot C E R_{e_{a}}^{\prime}-w_{a}\right]=0 \\
e_{a}^{*} \cdot C E R_{e_{a}}^{\prime}=\frac{w_{a}}{p^{E T S}}
\end{gathered}
$$

Now consider the agents and the profit for agents under this arrangement, where $\Pi^{a}\left(e_{a}\right)$ is the profit to the agents in this arrangement:

$$
\Pi^{a}\left(e_{a}\right)=w_{a} \cdot e_{a}+\beta \cdot\left[p^{E T S} \cdot \operatorname{CER}\left(e_{a}\right)-w_{a} \cdot e_{a}-F(A)\right]
$$

Rewriting (14) yields:

$$
\Pi^{a}\left(e_{a}\right)=(1-\beta) \cdot w_{a} \cdot e_{a}+\beta \cdot\left[p^{E T S} \cdot \operatorname{CER}\left(e_{a}\right)-F(A)\right]
$$

We can now find the optimal effort from the agents' point of view:

$$
\frac{d \Pi^{a}\left(e_{a}\right)}{d e_{a}}=(1-\beta) \cdot w_{a}+\beta \cdot\left[p^{E T S} \cdot C E R_{e_{a}}^{\prime}\right]=0
$$

Setting $\beta=0.5$, we have that 


$$
\begin{gathered}
\frac{d \Pi^{a}\left(e_{a}\right)}{d e_{a}}=0.5 \cdot w_{a}+0.5 \cdot\left[p^{E T S} \cdot C E R_{e_{a}}^{\prime}\right]=0 \\
e_{a}^{*} \cdot C E R_{e_{a}}^{\prime}=\frac{w_{a}}{p^{E T S}}
\end{gathered}
$$

In the particular case where $\beta=0.5$, there is an alignment of incentives between agent and investor, that is, it is in the interest of the agent to produce the $B M$ also preferred by the investor.

We consider this system to be a best practice incentive system for the following three reasons. First, the system creates a risk sharing arrangement. Consider that the relationship between biomass and agent effort is not deterministic, but stochastic, e.g., $B M\left(e_{a}\right)+\epsilon_{e_{a}}$ where $\epsilon_{e_{a}} \sim N\left(0, \sigma^{2}\right)$ such that for each choice of $e_{a}$, the expected realization of the $B M$ is $B M^{T}\left(e_{a}\right)$, but from the outset unpredictable events (draught, infestations, fire, etc.) will affect realization of the biomass. If agents, for example, provide effort $e_{a}^{*}$, but realization of $B M$ is less than expected, the agents will only have their wage income reduced by 0.5 per effort reduced. They will gain parts of the overall benefit as well and thereby still provide more than their reservation payment for a large interval of $e_{a}$ around $e_{a}^{*}$.

Secondly, the system provides income sharing. Another feature that makes this system interesting is that the most efficient situation, $e_{a}=e_{a}^{*}$, also yields the largest benefit to the local community, i.e. the agents. Thomas et al. (2010), who address why A/R projects only account for so few of the total CDM projects, point to financial, administrative and governance issues. A feature of "successful" CDM A/R projects is that most revenue from CERs must be directed back to the local community. Note that the equal split situation is not forced upon the parties, but is derived as the optimal solution given the incentive contract, which therefore also incorporates fairness considerations explicitly.

Finally, the system eliminates the main channel through which corruption might occur. Because the payment is contingent on output, there is no need for external supervision, and therefore no incentives to either hide real effort or the bribe the supervisor to report higher than observed effort.

\subsection{A Pilot Project in West Africa?}

Where should the incentive model derived above be applied first? West Africa could be a good place to start as it is naturally covered by savannah, woodland and forests. In fact, the FAO forest definition used under REDD+ implies that many areas usually referred to as woodland and savannahs are included under forest. A/R CDM projects have a huge potential in areas with degraded savannahs, woodlands and unproductive agricultural soils, where changes in land use may be an efficient means to sequestrate greenhouse gases, thereby decreasing the effects of climate change. In a global analysis, Sub-Saharan Africa was found to have a high suitability for A/R CDM projects (Zomer et al., 2008). Still, by the end of 2009, only one reforestation project has been approved in West Africa (UNEP, 2009). 
Lykke et al. (2009) have investigated seven sites in semi-arid African vegetation zones, which have been subject to different, known amounts of human impact and could be considered for $\mathrm{A} / \mathrm{R} \mathrm{CDM}$ projects. The general trend is that the current carbon stock decreases from the southern to the northern parts of West Africa, as may be expected from the climatic gradients of the region (increasing aridity towards the north). Even West Africa, which to a large extent is semi-arid, offers an important opportunity for climate change mitigation through $\mathrm{A} / \mathrm{R} \mathrm{CDM}$ projects. Areas with high human population density show the greatest potential for biomass increases as human activities can significantly decrease the biomass through clearance of forests for agriculture, overgrazing, frequent burning and logging. The results show that management aimed at reducing the negative anthropogenic impacts on vegetation cover could lead to substantial increases in vegetation biomass. Lykke et al. (2009) concludes that in a longer time perspective the income from harvesting the forest will far exceed CDM investment if the tree planting and subsequent resource management is well organized.So, overall, if A/R CDM projects become a success in practice, they are most likely to further increase the investments in developing countries, such as semi-arid Africa, and eventually lead to a shift towards more sustainable land management and poverty alleviation.

The three institutional shortcomings from the model (income sharing, risk sharing and corruption prevention) have to be dealt with. First, the shortcoming of income sharing is problematic. Local communities are often reluctant to support CDM projects doubting that they will ever receive any economic net gain from doing so. In earlier projects, there have indeed been cases where local farmers did not receive their fair share of the new income, and in some cases, they have even been excluded from harvesting the new forests.The specific question concerning a CDM project is how to share the income from selling CERs back to the local communities so to get incentives right. Here, proper investments in e.g. cottage industries that process products extracted from the forest could be considered. Furthermore, access to local markets and trade over distance could be improved by investing in better infrastructure thus facilitating more jobs. In developing countries, carbon sequestration and poverty alleviation must overall happen side by side (Basu 2009). Future research should therefore try to deal with fair sharing of income (Lykke et al., 2009).

Second, large uncertainties and the lack of risk sharing may discourage land users from investing in forestry such as fires, draughts, infestations etc. Especially fires increase carbon emissions substantially calling for better fire management. Africa alone is responsible for $40 \%$ of the fire-induced carbon released into the atmosphere (Williams et al., 2007). Also the potential of sequestration may change rapidly over time as temperatures are predicted to rise and precipitation to decrease. This has already been the trend in West Africa over the last decades (Walker et al., 2008).

Third, corruption reduces environmental regulatory stringency and undermines the effectiveness of management systems when reducing social and economic cost of breaking established rules According to UNEP (2013), the overall result from empirical research is that corruption levels and deforestation are heavily correlated. Remote sensing is, however, a way of circumventing the corruption problem and also facilitates income and risk sharing as 


\section{Ml Macrothink}

Environmental Management and Sustainable Development

ISSN 2164-7682

argued above. Thus, the institutional shortcoming of corruption is no longer a serious barrier regarding the introduction of a CDM pilot project in West Africa

\section{Conclusion}

Our main motivation was to turn attention to the huge CDM potential in developing countries.

The main question was how to increase the likelihood of CDM approval in the face of institutional shortcomings? This question has largely been neglected by the literature so far. While A/R CDM projects have large potentials, they also face three main institutional shortcomings, namely income sharing, risk sharing and corruption prevention. We argued based on a principal-agent model that the key to deal with these three institutional shortcomings lays in the possibility of necessary monitoring and enforcement capacity.

Regarding reforestation projects in particular, the possibility of remote sensing seems to be a new and effective tool to enhance the profitability and success of the CDM and the precise measurement of carbon storage in biomass. To test the possibility of A/R CDM projects in Africa and to develop a best practice system, we suggested that an appropriate site is chosen for pilot projects in West Africa due to its high potential.

If such a pilot project turns out positive, the West Africa model may be included as a new best practice option and be exported to other regions as well. We thus urge negotiators at the upcoming $\mathrm{COP}$ meetings to consider remote sensing as a crucial tool for future CDM projects.

\section{References}

Anger, N, A. Dixon \& E. Livengood. (2012). 'Reduced deforestation and the carbon market: the role of market regulations and future commitments', Environment and Development Economics, 17, 269-292.

Basu, P. (2009). A green investment. Nature, 457, 144-145.

Brandt, U.S., \& G.T. Svendsen. (2013a). Why only few CDM projects? The case of reforestation projects and remote sensing'. International Journal of Global Environmental Issues, 13, 25-42.

Brandt, U.S., \& G.T. Svendsen. (2013b). Why does bureaucratic corruption occur in the EU? A principal-supervisor-agent model. Public Choice, 157, 585-599.

Buchner, B.K. (2008). 'CDM - A Policy to Foster Sustainable Development?', In Clini, C., I. Musu and M.L. Gullino (eds.): Sustainable Development and Environmental Management, Springer Verlag.

Conyon, M. J. \& He, L. (2004). Compensation Committees and the CEO: Compensation Incentives in the US Entrepreneurial Firms. Unpublished working paper.

Cormier, A., \& Bellassen, V. (2013). The risks of CDM projects: How did only 30\% of expected credits come through? Energy Policy, 54, 173-183. 
$\begin{array}{llllll}\text { FAO. (2012). State of the world's } & \text { Forests } 2012 .\end{array}$ http://www.fao.org/docrep/016/i3010e/i3010e00.htm. (access date: July 1, 2013)

Gong, Y. (2010). Participation in the world's first clean development mechanism forest project: the role of property rights, social capital and and contractual rules. Ecological Economics, 69, 1292-1302.

Höhne, N., Wartmann, S., Herold, A., \& Freibauer, A. (2007). The rules for land use, land use change and forestry under the Kyoto protocol - lessons learned for the future climate negotiations. Environmental Science and Policy, 10, 353-369.

Kanowski, P. J., C. L. McDermott, \& B.W. Cashore. (2011). Implementing REDD+: Lessons from Analysis of Forest Governance. Environmental Science \& Policy, 14, 111-117.

Lederer, M. (2011). From CDM to REDD+ - what do we know for setting up effective and legitimate carbon governance? Ecological Economics, 70, 1900-1907.

Lykke, A.M., Barfod, A.S., Svendsen, G.T., Greve, M., \& Svenning, J. (2009). Climate change mitigation by carbon stocking. Earth and Environmental Science, 8, 1-17.

Paulsson, E. (2009). A review of the CDM literature: from fine tuning to critical scrutiny, International Environmental Agreements, 9, 63-80.

Perman, R., Y. Ma, J. McGilvray \& M. Common. (2011). Natural Resources and Environmental Economics. Pearson: London. ( $4^{\text {th }}$ edition).

Paarsch, J.H., \& Shearer, B. (1996). Piece Rates, Fixed Wages, and Incentive Effects: Statistical Evidence from Payroll Records. Cirano scientific Series, 96s-31, Montréal.

Palmer, C. (2011). Property rights and liability for deforestation under REDD+: implication for'permanence' in policy design. Ecological Economics, 70, 571-576.

Risoe. (2012). CDM/JI Pipeline Overview http://www.cdmpipeline.org/overview.htm\#3. (access date: July 1, 2013)

Thomas, T., Dargusch, P., Harrison, S., \& Herbohn, J. (2010). Why are there so few a forestation and reforestation clean development mechanism projects? Land Use Policy, 27, 880-887.

Torres, A.B., Marchant, R., Lovett, J.C., Smart, J.C.R., \& Tipper, R. (2010). Analyses of e carbon sequestration costs of a forestation and reforestation agroforestry practices and the use of cost curves to evaluate their potential for implementation of climate change mitigation. Ecological Economics, 69, 469-477.

UNEP Risø Centre. (2009). CDM pipeline.www.cdmpipeline.org.

UNEP. (2013). The impact of corruption on climate change: Threatening emissions trading mechanisms? Environmental Development. In press. 


\section{Macrothink \\ Environmental Management and Sustainable Development \\ ISSN 2164-7682 \\ 2014, Vol. 3, No. 1}

Walker, SM, Pearson, TRH, Munishi, P, \& Petrova, S. (2008). Carbon market opportunities for the forestry sector of Africa. Winrock International. FAO African Forestry and Wildlife Commission 16th Session, Khartoum, Sudan 17-24 February 2008.

Williams, C., Hanan, N. P., Neff, J. L., Scholes, R, Berry, J. A., Denning, A. S. \& Baker, F. B. (2007) Africa and the global carbon cycle. Carbon Balance Manag, 2, 1-13.

Zomer, R. J., Trabucco, A., Bossio, D. A., \& Verchot, L. V. (2008). Climate change mitigation: a spatial analysis of global land suitability for clean development mechanism a forestation and reforestation. Agric Ecosys Environ, 126, 67-80.

\section{Copyright Disclaimer}

Copyright reserved by the author(s).

This article is an open-access article distributed under the terms and conditions of the Creative Commons Attribution license (http://creativecommons.org/licenses/by/3.0/). 